\author{
О.А. Дакі ${ }^{1}$, В.М. Іваненко ${ }^{1}$, В.М. Федунов ${ }^{1}$, М.П. Карпін ${ }^{2}$, Є.А. Толкаченко ${ }^{3}$ \\ ${ }^{1}$ Державний університет інфраструктури та технологій, Київ \\ ${ }^{2}$ Національний університет оборони Украӥни ім. І. Черняховського, Київ \\ ${ }^{3}$ Харківський національний університет Повітряних Сил ім. І. Кожедуба, Харків
}

\title{
СИНТЕЗ АЛГОРИТМІВ СИСТЕМИ КОНТРОЛЮ ТА УПРАВЛІННЯ СУДНОВИМИ СИСТЕМАМИ
}

\begin{abstract}
У статті визначено, щчо поява надійних, перешкодостійких та економічних аналогових і логічних мікросхем, мікропроцесорної техніки, вдосконалення та мініатюризація виконавчих електромеханічних елементів й датчиків надали якісно нову елементну базу для сучасного етапу розвитку автоматизачії суднових систем, а саме розроблення алгоритмів системи контролю та управління судновими системами. 3 впровадженням мікроелектронних електронно-обчислювальних машин в суднові системи управління став характерний комплексний системний характер автоматизації, збалансований розподіл функцій управління між людиною та керуючою електронно-обчислювальною машиною з урахуванням ергономічних, психологічних та економічних вимог, використання математичних моделей управління та автоматичного пошуку оптимуму за заданим критерієм, використання самоналагоджувальних структур. Через тенденцію скорочення чисельності обслуговуючого персоналу; необхідність обмеження потоку інформації, а також здійснення дій; вимоги обмеження масо-габаритних характеристик пультів управління, шчитів, панелей, а також необхідність реєструвати зміну багатьох параметрів підсистем зумовило створення системи обробки представлення інформації. Для адекватного функиіонування синтезованої системи управління у статті розроблені алгоритми первинної обробки інформації, яка надходить від датчиків. Ці алгоритми повинні забезпечувати вироблення екстрених повідомлень судноводієві в разі, коли порушується нормальний режси роботи та виникає передаварійна ситуація. 3 метою отримання адекватних технічних рімень потрібне створення моделей та алгоритмів оптимізації й автоматизації суден і суднових технічних засобів, способів побудови систем на основі сучасних технологій суднового машинобудування, розробки алгоритмів для підвищення оперативності прийняття рішення судноводієм.
\end{abstract}

Ключові слова: автоматизація, вахтова служба, система контролю, система управління, судноводій.

\section{Вступ}

Постановка проблеми. Поява надійних, перешкодостійких та економічних аналогових і логічних мікросхем, мікропроцесорної техніки, вдосконалення та мініатюризація виконавчих електромеханічних елементів й датчиків надали якісно нову елементну базу для сучасного етапу розвитку автоматизації суднових систем суден. Даний етап почався зі впровадження мікроелектронних електроннообчислювальних машин в суднові системи управління. Для нього характерні такі особливості:

- комплексний системний характер автоматизації, що охоплює всі сторони функціонування судна як специфічного транспортного засобу з усіма взаємозв'язками;

- збалансований розподіл функцій управління між людиною та керуючою електроннообчислювальною машиною з урахуванням ергономічних, психологічних та економічних вимог;

- використання математичних моделей управління та автоматичного пошуку оптимуму за заданим критерієм, використання самоналагоджувальних структур та структур, які навчаються.

Суднові системи представляють собою складні системи, від якісного контролю яких судноводієм у процесі несення вахтової служби залежить своєчасність та вірність прийнятих рішень. Важливим елементом контролю є обробка інформації, яка надходить від датчиків суднових систем та вироблення екстрених повідомлень судноводієві під час несення вахти.

Аналіз останніх досліджень і публікацій. У розробку різних аспектів проблеми автоматизації систем управління судновими системами внесли вклад вчені: Бажан П.В., Басін А.М., Большаков В.Ф., Бутов О.С., Вагущенко Л.Л., Клімов Є.М., Матвєєв Ю.І., М'ясників Ю.М., Петров Ю.П., Попов С.А., Плющаєв В.І., Роннов С.П., Сазонов А.С., Чиркова М.М., Фейгін I.А. та ін. [1-5].

Результати даних досліджень стали підгрунтям до якісно нового рівня автоматизації, у тому числі реагування на кризові ситуації з використанням системи контролю.

Метою дослідження є розроблення алгоритмів системи контролю та управління судновими системами.

\section{Виклад основного матеріалу}

Під алгоритмічною структурою контролю та управління будемо розуміти сукупність алгоритмів окремих режимів роботи технологічного процесу із 
зазначенням умов переходу від одного режиму роботи до іншого. При вимірі технологічних параметрів підсистем судна інформація від датчиків надходить в апаратуру введення/виведення у вигляді уніфікованих сигналів (0-10, 4-20 мА, тощо), сигналів від термопар, термометрів опору, тобто реальною фізичною величиною є напруга, сила струму, індуктивність або частота імпульсів [6]. У пристроях зв'язку з об'єктом (ПЗО) ці сигнали перетворюються в двійкові коди довжиною від 8 до 16 розрядів.

Щоб провести аналіз інформації, яка отримується, необхідно перетворити коди аналоговоцифрового перетворювача (АЦП) у масштаб реальних фізичних величин. До того ж датчики можуть мати статичні помилки, нелінійні характеристики або вихідний зашумлений сигнал [7]. Для отримання коректних значень результатів моніторингу 3 двійкових кодів ПЗО застосуємо алгоритми первинної обробки - перевірку на достовірність, згладжування, перевірку на технологічні межі. Програмну реалізацію алгоритмів контролю і управління виконаємо в математичному пакеті "MatLab 7.0.1" з метою пере- вірки їх працездатності.

Для адекватного функціонування синтезованої системи управління необхідно розробити алгоритми первинної обробки інформації, що надходить від датчиків. Ці алгоритми повинні забезпечувати вироблення екстрених повідомлень судноводієві в разі, коли порушується нормальний режим роботи та виникає передаварійна ситуація [8].

Сигнали від датчиків надходять по фізичних лініях на АЦП. На ці сигнали накладаються різні перешкоди (імпульсні перешкоди; радіоперешкоди промислових частот; перешкоди, обумовлені похибкою датчиків). Сигнал з АЦП обробляється в ЕОМ, i для того, щоб усунути вплив перешкод, розробляються алгоритми контролю. До них відносяться алгоритми перевірки на достовірність, фільтрації та перевірки на технологічні межі. Для введення аналогового сигналу необхідно здійснити ініціалізацію АЦП і встановити коефіцієнт посилення підсилювача по відповідному каналу введення.

Наведемо блок-схему алгоритму введення сигналів від датчиків на рис. 1 .

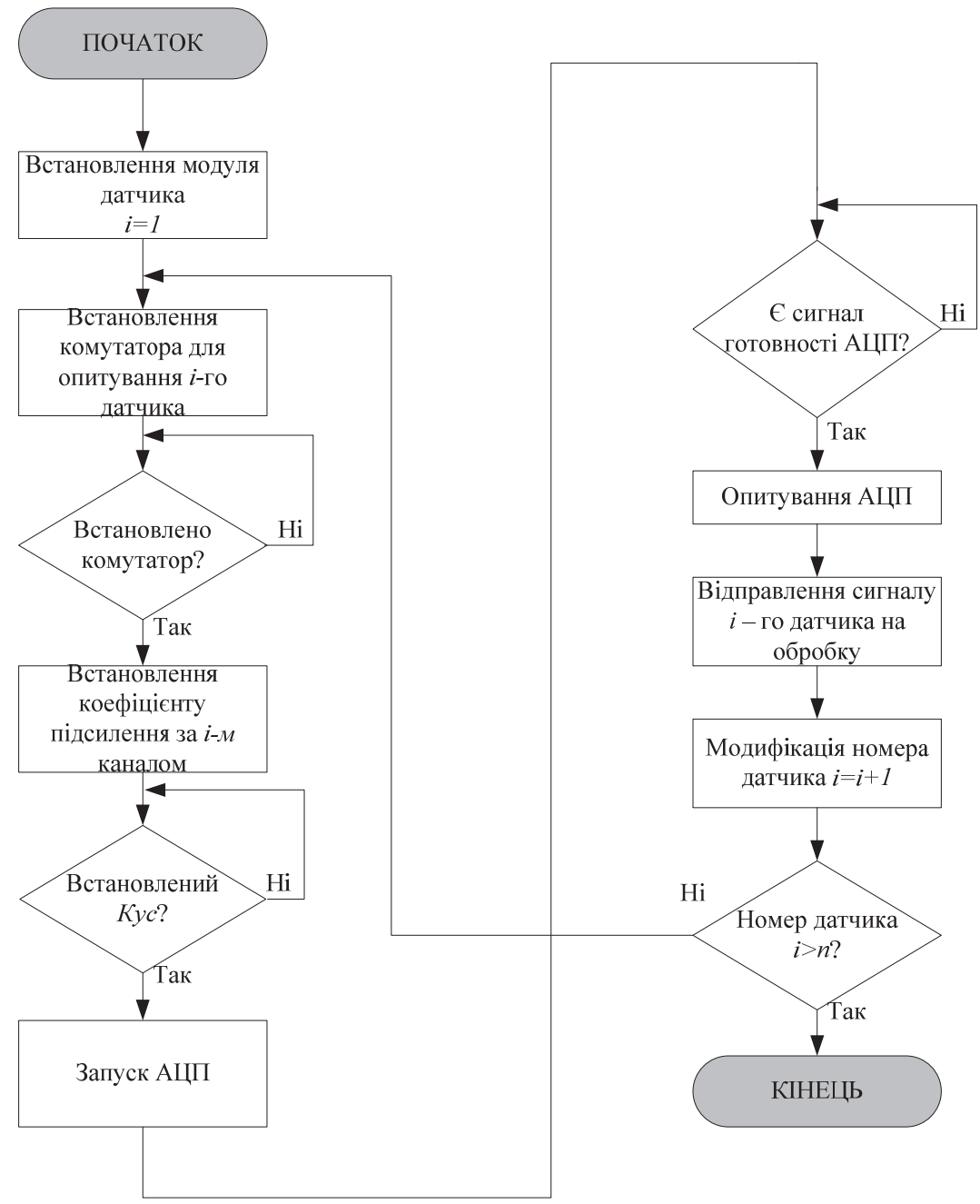

Рис. 1. Блок-схема алгоритму введення сигналів від датчиків Джерело: розроблено авторами.

Сигнали, які надходять від датчиків, піддаються первинній обробці, алгоритми якої опишемо далі.

Алгоритми перевірки на достовірність та філь- трації. Алгоритм перевірки на достовірність служить для визначення наявності імпульсної перешкоди та іï усунення, для виявлення короткого замикан- 
ня або обриву в каналі зв'язку [9]. При перевірці здійснюється циклічне опитування всіх датчиків. Інтервал перевірки на достовірність визначається як $K-T_{\text {onm }}$, де $T_{\text {опm }}$ - час опитування датчику, а коефіцієнт $K$ оцінюється, виходячи $з$ динамічних характеристик у кожному каналі (можна вибрати максимальне для всіх каналів значення). Перші $K$ значень приймаються достовірними. Перевірка виконується за умовою:

$$
\left|X_{i(j-K)}-X_{i j}\right|<\Delta X_{\text {допi }}
$$

де $i$ - номер датчика;

$$
j \text { - номер відліку }(j=K+1, K+2 \ldots) \text {. }
$$

Якщо умова (1) порушується, то вводиться ознака порушення та лічильник кількості порушень.
Замість $X_{i j}$ записується останнє достовірне значення. Потім перевіряється наступний сусідній відгук на умову (1).

Якщо в черговий раз умова порушується, то лічильник порушень додається, і знову ж записується останнє достовірне значення. Якщо кількість порушень досягло трьох поспіль, то приймається рішення про наявність стійкої перешкоди. Тоді аналізується знак різниці (1) і визначається вид перешкоди: якщо “+”"- коротке замикання, якщо “-”- обрив. При цьому в пам'яті ЕОМ фіксується час порушення i номер каналу, в якому воно виявлено.

Відповідно до цього блок-схема алгоритму перевірки на достовірність наведена на рис. 2.

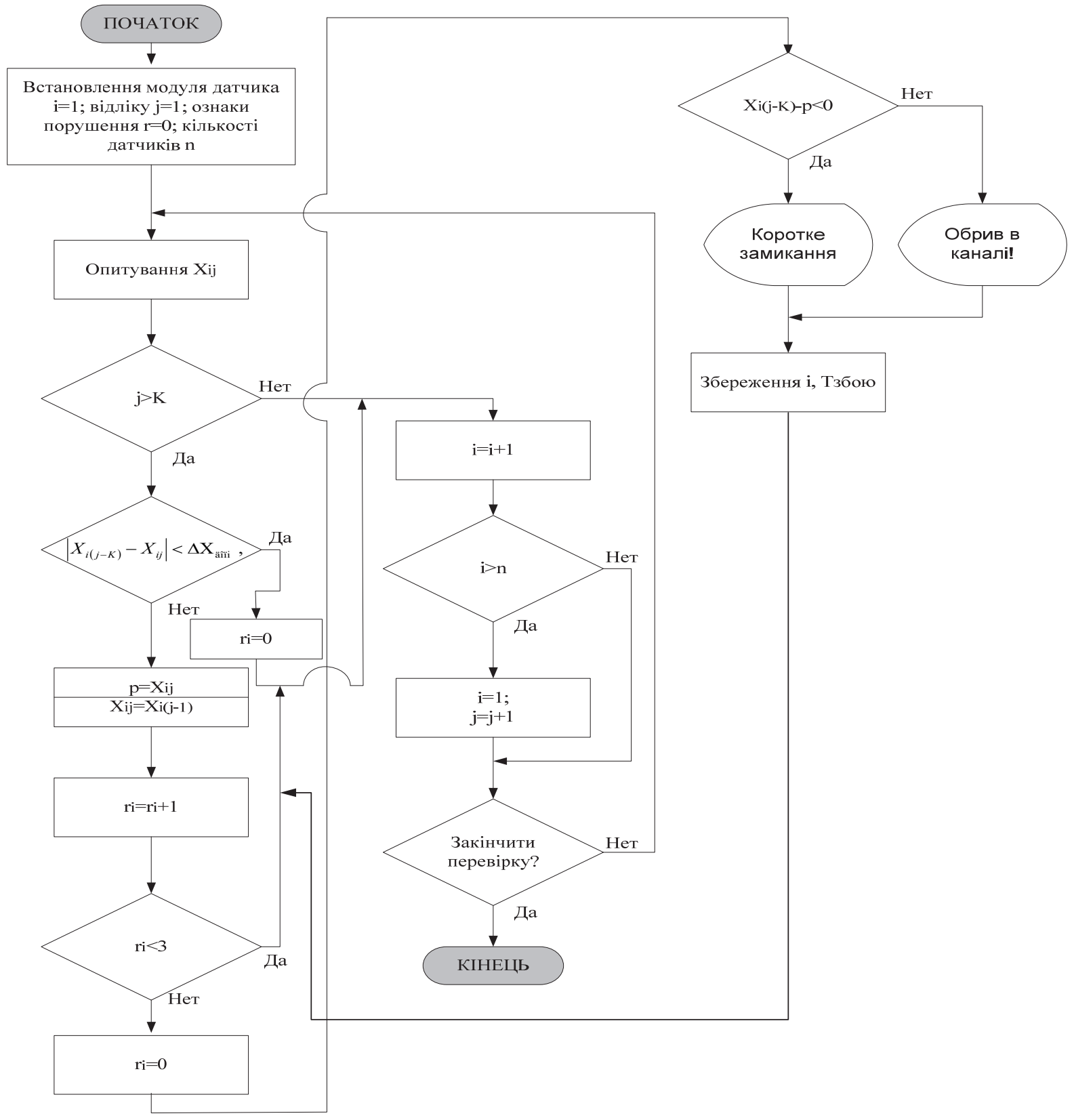

Рис. 2. Блок-схема алгоритму перевірки на достовірність Джерело: розроблено авторами. 
Моделювання роботи алгоритму здійснено в середовищі “MatLab 7.0.1”. Сигнали від датчиків було імітовано при наявності випадкових збоїв, обривів і коротких замикань каналу (рис. 3).
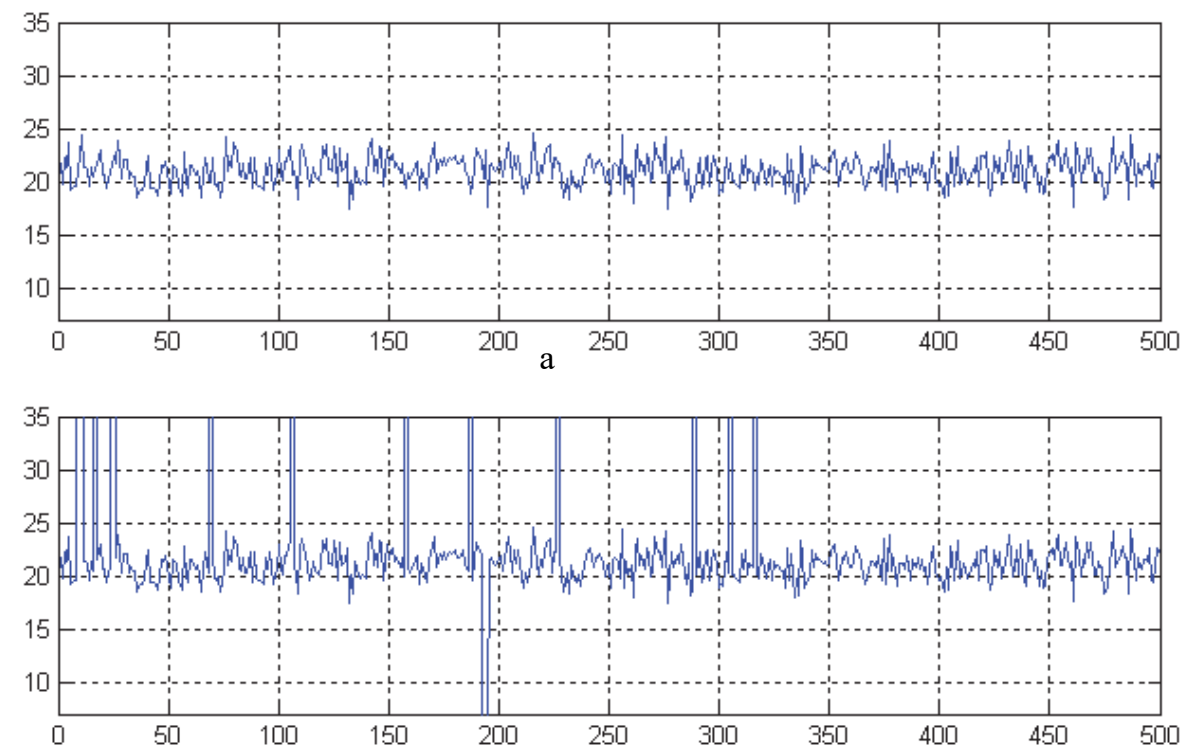

6

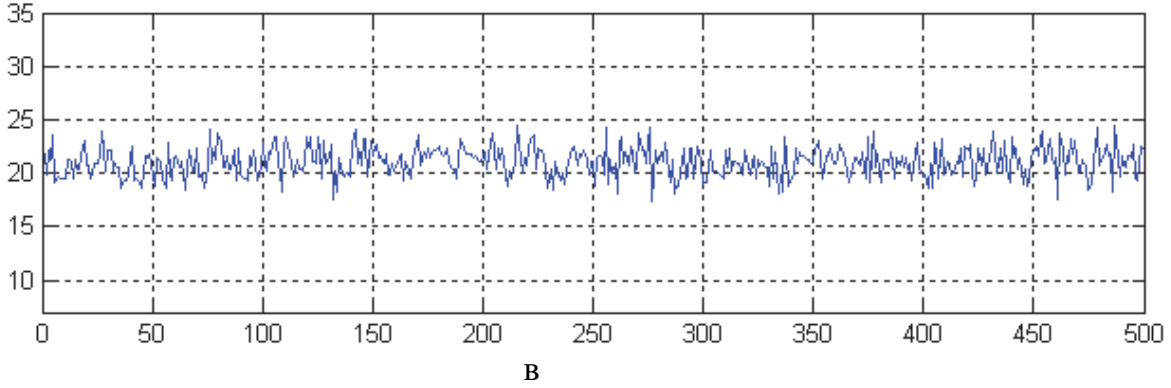

Рис. 3. Результати моделювання роботи алгоритму перевірки на достовірність: a - сигнал на виході датчика; б - сигнал в каналі вимірювань; в - сигнал перевірений на достовірність Джерело: розроблено авторами.

На рис. 3, а наведений сигнал від датчика температури повітря машинно-котельного відділення судна; на рис. 3, б відображена імітація обриву і короткого замикання в каналі зв'язку сигналу від датчика температури повітря; на рис. 3 , в) наведений вид сигналу після виконання алгоритму перевірки на достовірність. У результаті моделювання роботи алгоритму перевірки на достовірність були виявлені всі імпульсні перешкоди та отримано “чистий” сигнал для подальшої обробки. При роботі технологічних об'єктів створюються перешкоди. Для усунення високочастотних перешкод використовуються апаратні RC-фільтри. Але вони не здатні послабити перешкоди з частотами, близькими до частот корисних сигналів. Найпростішим прикладом такої перешкоди є похибка вимірювання параметрів технологічного процесу. Для ослаблення такого роду перешкод зазвичай використовуються алгоритми змінного середнього або експоненціального згладжування.

\section{Алгоритм перевірки на технологічні межі}

Кожна вимірювана величина технологічного процесу змінюється в заданих межах. Якщо параметр виходить за бажаний діапазон, виникає небез- пека порушення процесу роботи системи. Тому судноводій (вахта) повинен вчасно вжити заходів щодо усунення порушень. Для цього розробляється алгоритм перевірки на технологічні межі. Допустимо, вимірюваний параметр повинен змінюватися в діапазоні: $D_{x}=X \mu_{k}-X \varepsilon_{k}$, тоді якщо поточне значення $X_{i k}$ ( $i$ - номер відліку, $k$ - канал вимірювання) лежить в межах $X \mu_{k}-X \beta_{k}$ і виконується умова:

$$
X \mu_{k}+\delta_{\kappa} \gamma_{i-1} \leq X_{i k} \leq X \beta_{k}-\delta_{k} \gamma_{i-1},
$$

де $\delta_{k}$ - смуга гістерезису дорівнює 5\% від діапазону зміни параметра;

$\gamma_{i-1}-$ значення ознаки порушення кордону для попереднього відліку.

У цьому випадку судноводій (вахта) не отримує повідомлень, і поточне значення ознаки порушення границі $\gamma_{i}=0$. Якщо $X_{i k}>X_{6 i}$ або $X_{i k}<X_{b i}$, то подається сигнал тривоги, $\gamma_{i}=1$. При виході сигналу за задані межі в пам'яті фіксується час порушення, канал, в якому воно відбулося, а також яка межа була порушена.

Блок-схема алгоритму перевірки на технологічні межі наведена на рис. 4. 


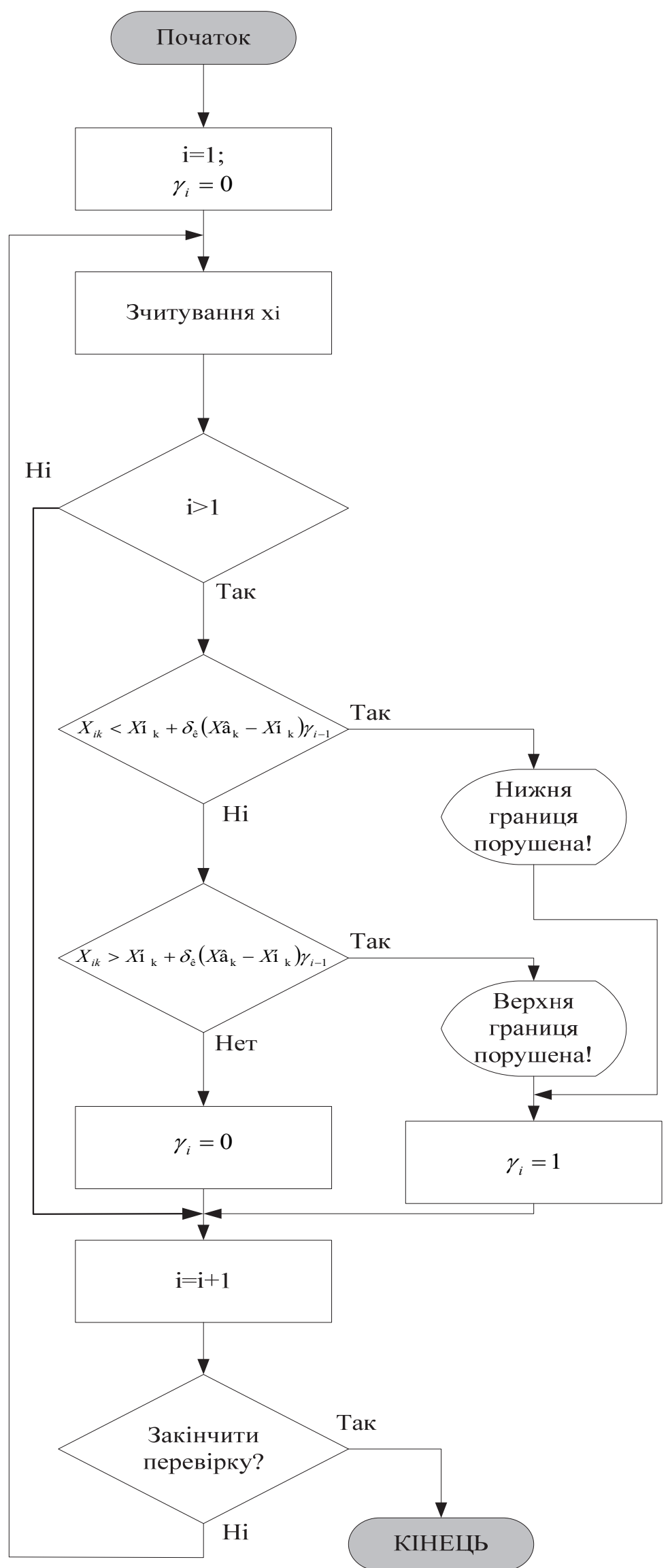

Рис. 4. Блок-схема алгоритму перевірки на технологічні межі Джерело: розроблено авторами. 


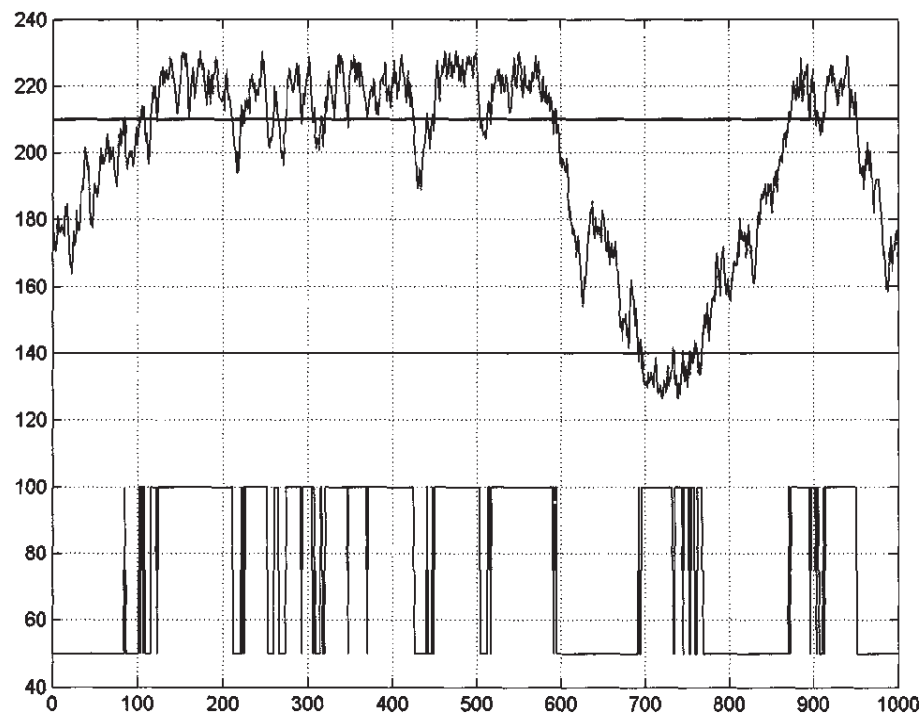

Рис. 5. Результати моделювання алгоритму перевірки на технологічні межі Джерело: розроблено авторами.

Результати моделювання роботи програми в середовищі "MatLab 7.0.1” наведено на рис. 5.

На першому графіку (рис. 5) показана імітація сигналу датчика тиску повітря в трубопроводі машинно-котельного відділення, а на другому - зміна стану ознаки переходу $\gamma$.

\section{Висновки}

Тенденція до подальшого скорочення чисельності обслуговуючого персоналу; необхідність обмеження потоку інформації до рівня, що визначається можливостями судноводія щодо сприйняття та переробки інформації, а також здійснення дій; вимо- ги обмеження масо-габаритних характеристик пультів управління, щитів, панелей, а також необхідність реєструвати зміну багатьох параметрів підсистем.

Все це зумовило створення системи обробки представлення інформації.

Для одержання адекватних технічних рішень потрібне створення моделей та алгоритмів оптимізації й автоматизації суден і суднових технічних засобів, способів побудови систем на основі сучасних технологій суднового машинобудування, розробки алгоритмів для підвищення оперативності прийняття рішення судноводієм.

\section{Список літератури}

1. Вагущенко Л. Л., Цымбал Н. Н. Системы автоматического управления движением судна. 3-е изд., перераб. и доп. Одесса : Феникс, 2007. 328 с.

2. Вагущенко Л. Л., Вагущенко А. Л., Заичко С. И. Бортовые автоматизированные системы контроля мореходности. Одесса : Феникс, 2005. 272 с

3. Вагущенко Л. Л. Интегрированные системы ходового мостика. Одесса : Латстар, 2003. 169 с.

4. Сахаров В. В., Кузьмин А. А., Чертков А. А. Модели и алгоритмы оптимизации технологических процессов на объектах водного транспорта в среде MATLAB : монография / Санкт-Петербург : ГУМРФ им. С.О. Макарова, 2015. 436 с.

5. Рудницкий А. В., Рудницкий В. И., Федосенко Ю. С. Стохастические модели оценки эксплуатационной готовности в системе управления технической эксплуатацией группы судов. Вестник Волжской государственной академии водного транспорта. 2016. № 49. С. 61-68.

6. Ищенко А. С., Чиркова М. М. Интеллектуальная поддержка принятия решения в задаче контроля и управления работой главного судового двигателя. Вестник Волжской государственной академии водного транспорта. 2005. № 14. С. 49-54.

7. Gupta M. M., Sinha N. K. Intelligent control systems: theory and applications. New York : IEEE, 1996. 820 p.

8. Sutton R. S., Barto A. G. Reinforcement Learning: An Introduction. London : The MIT Press, 2008. 322 p.

9. Одинаев В. А. Математическая модель пространства состояний судовой электроэнергетической системы. Принятие оперативных решений. Судостроение. 2003. № 5. С. 42-44.

10. Субботін С. О. Подання та обробка знань у системах штучного інтелекту та підтримки прийняття рішень. Запоріжжя : ЗНТУ, 2008. $341 \mathrm{c}$.

11. Pavlenko M., Kolmykov M., Tymochko O., Khmelevskiy S., Larin V. Conceptual Basis of Cascading Differential Masking Technology, 2020 IEEE 11th International Conference on Dependable Systems, Services and Technologies (DESSERT). 14-18 May 2020. Kyiv, 2020. https://doi.org/10.1109/dessert50317.2020.9125024.

12. Павленко М. А., Осієвський С. В., Данюк Ю. В. Методологічні основи підвищення якості програмного забезпечення інтелектуальних систем прийняття рішення. Системи обробки інформації. 2021. № 1(164). С. 55-64. https://doi.org/10.30748/soi.2021.164.06. 
Відомості про авторів:

\section{Дакі Олена Анатоліївна}

доктор технічних наук професор

директор Дунайського інституту водного транспорту

Державного університету інфраструктури та технологій, Київ, Україна

https://orcid.org/0000-0003-3932-462X

Іваненко Віталій Миколайович

старший викладач

Державного університету інфраструктури та технологій, Київ, Україна

https://orcid.org/0000-0003-3271-5257

\section{Федунов Валерій Миколайович}

старший викладач

Державного університету інфраструктури та технологій,

Київ, Україна

https://orcid.org/0000-0001-5092-2511

Карпін Микола Петрович

старший викладач Національного університету

оборони України ім. І. Черняховського,

Київ, Україна

https://orcid.org/0000-0002-4863-1528

Толкаченко Євгеній Анатолійович

доктор філософії

викладач Харківського національного університету

Повітряних Сил ім. І. Кожедуба,

Харків, Україна

https://orcid.org/0000-0003-3736-2606

\section{Information about the authors:}

\section{Olena Daki}

Doctor of Engineering Science Professor

Director of Danube Institute of Water Transport State

University of Infrastructure and Technologies,

Kyiv, Ukraine

https://orcid.org/0000-0003-3932-462X

Vitaliy Ivanenko

Senior Lecturer

of State University of Infrastructure and Technologies,

Kyiv, Ukraine

https://orcid.org/0000-0003-3271-5257

Valerii Fedunov

Senior Lecturer

of State University of Infrastructure and Technologies,

Kyiv, Ukraine

https://orcid.org/0000-0001-5092-2511

Mykola Karpin

Senior Lecturer of the National Defense University

of Ukraine named after Ivan Chernyakhovsky,

Kyiv, Ukraine

https://orcid.org/0000-0002-4863-1528

Yevhenij Tolkachenko

Philosophy Doctor

Lecturer of Ivan Kozhedub Kharkiv

National Air Force University,

Kharkiv, Ukraine

https://orcid.org/0000-0003-3736-2606

\section{СИНТЕЗ АЛГОРИТМОВ СИСТЕМЫ КОНТРОЛЯ И УПРАВЛЕНИЯ СУДОВЫМИ СИСТЕМАМИ}

\section{Е.А. Даки, В.Н. Иваненко, В.Н. Федунов, Н.П. Карпин, Е.А. Толкаченко}

В статье определено, что появление надежных, помехоустойчивых и экономических аналоговых и логических микросхем, микропроиессорной техники, усовериенствование и миниатюризаиия исполнительных электромеханических элементов и датчиков предоставили качественно новую элементную базу для современного этапа развития автоматизаиии судовых систем, а именно разработку алгоритмов системы контроля и управления судовыми системами. С внедрением микроэлектронных электронно-вычислительных машин в судовые системы управления стал характерный комплексный системный характер автоматизации, сбалансированное распределение функиий управления между человеком и управляющей электронно-вычислительной машиной с учетом эргономических, психологических и экономических требований, использования математических моделей управления и автоматического поиска оптимума по заданному критерию, использование самоналадочных структур. Из-за тенденции сокращения численности обслуживающего персонала; необходимость ограничения потока информации, а также совериение действий; требования ограничения массо-габаритных характеристик пультов управления, шитов, панелей, а также необходимость регистрировать изменение многих параметров подсистем обусловило создание системы обработки представления информации. Для адекватного функиионирования синтезированной системы управления в статье разработаны алгоритмы первичной обработки информации, поступающей от датчиков. Эти алгоритмы должсны обеспечивать выработку экстренных сообщений судоводу в случае, когда нарущается нормальный режим работы и возникает предаварийная ситуация. $B$ иелях получения адекватных технических решений необходимо создание моделей и алгоритмов оптимизации и автоматизации судов и судовых технических средств, способов построения систем на основе современных технологий судового машиностроения, разработки алгоритмов для повышения оперативности принятия решения судоводителем.

Ключевые слова: автоматизация, вахтенной службы, система контроля, система управления, судоводитель.

\section{SYNTHESIS OF CONTROL AND MANAGEMENT ALGORITHMS OF SHIPBOARD SYSTEMS}

O. Daki, V. Ivanenko, V. Fedunov, M. Karpin, Ye. Tolkachenko

The article states that the emergence of reliable, noise-tolerant and economical analog and logic chips, microprocessor technology, improvement and miniaturization of electromechanical actuators and sensors provided a qualitatively new elemental basis for the current stage of automation of ship systems, namely the development of control and management system. With the introduction of microelectronic computers in ship control systems has become characterized by a complex systemic nature of automation, a balanced distribution of control functions between man and the controller, taking into account ergonomic, psychological and economic requirements, the use of mathematical control models and automatic optimum search, the use of self-tuning structures. Due to the tendency to reduce the number of service personnel; the need to limit the flow of information, as well as action; requirements for limiting the mass and dimensional characteristics of control panels, panels, panels, as well as the need to register changes in many parameters of the subsystems led to the creation of a system for processing the presentation of information. For the adequate functioning of the synthesized control system, the article develops algorithms for primary processing of information coming from sensors. These algorithms should ensure that emergency messages are generated to the driver in the event of a normal operation and a pre-emergency situation. In order to obtain adequate technical solutions it is necessary to create models and algorithms for optimization and automation of ships and ship equipment, ways to build systems based on modern technologies of ship engineering, development of algorithms to increase the efficiency of decision making by the driver.

Keywords: automation, watch service, control system, management system, navigator. 